\title{
¿Ha sido derrotada la teoría clásica del Derecho natural por el argumento de la falacia naturalista?
}

\section{Has the Naturalistic Fallacy Refutation Truly Defeated Classical Natural Law Theory?}

\author{
Carlos A. CASAnOva \\ (Universidad Santo Tomás y Universidad Bernardo O’Higgins, Chile)
}

Recibido: 19/12/2013

Aceptado: 27/02/2014

\section{Resumen}

Este escrito considera y distingue dos objeciones que de ordinario se piensa que se dirigen contra una concepción ética realista: la falacia naturalista de G. E. Moore y la ley de Hume. Después de haber expuesto ambas objeciones, desplegado sus supuestos y consecuencias y respondido a todos ellos, concluye que es posible hoy sostener una ética realista. Se estructura a la manera de una cuestión disputada, dividida en seis artículos.

Palabras clave: G. E. Moore, noción de bien, ley de Hume, ética realista, razón práctica.

\section{Abstract}

This paper considers and distinguishes two objections which ordinarily are thought to oppose a realistic conception of ethics: G. E. Moore's naturalistic fallacy and Hume's law. After having presented both objections, having developed their presuppositions and consequences and having answered each of them, the paper concludes that it is possible to hold today a realistic conception of ethics. It is structured in the style of a disputed question, divided in six articles.

Keywords: G. E. Moore, notion of the good, Hume's law, realistic ethics, practical reason. 
En las páginas que siguen vamos a considerar un grupo de problemas que tienen que ver con la existencia y aun la posibilidad de una ética realista. Todos conocen, más o menos, que en los dos y medio últimos siglos se han puesto en cuestión esas existencia y posibilidad, aduciendo que del ser o de las cosas que existen realmente no se puede seguir el deber ser. La mayoría piensa, además, que ése es el conocido argumento de la falacia naturalista. Aquí distinguiremos del mejor modo posible dos argumentos diferentes que se conocen en los círculos filosóficos como la "falacia naturalista", que acuñó G. E. Moore, y la "ley de Hume". Vamos a exponerlos y vamos a darles respuesta.

Realizaremos una breve presentación de los contextos en que se adelantaron ambos argumentos, y la combinaremos con una cuestión disputada, dividida en varios artículos muy compactos, que desplieguen las diversas facetas y dificultades que entraña este asunto, y que se estructurarán siguiendo el modelo que nos dejaron las obras de santo Tomás. La presentación de los contextos consistirá en un breve resumen, por una parte, de algunos aspectos de la obra Principia Ethica de G. E. Moore, y, por otra, de algunos presupuestos de la obra de David Hume e Immanuel Kant.

\section{Principia Ethica, de G. E. Moore}

Contrariamente a lo que se supone de ordinario, Moore no escribió esta obra para refutar el Derecho natural clásico. La escribió, más bien, para refutar el utilitarismo hedonista, el psicologismo, el sociologismo, una cierta clase de hegelianismo y el kantismo. Según este autor, la moral se ocupa de dos preguntas: qué cosas son buenas y deben ser promovidas, y cómo deben las acciones humanas promover esas cosas que son buenas. Las cosas buenas lo son porque se encuentra presente en ellas una propiedad, el bien, que es simple, que no es una realidad natural y que no es susceptible de definición ( $\S \S 6,8,9,13)$. Con base en todas estas características del bien, Moore refuta las diversas escuelas morales en boga en su época, arguyendo que incurren en la "falacia naturalista". Según él, demasiados filósofos han identificado el bien con otras propiedades que quizá siempre acompañen a las cosas que son buenas, incurriendo así en una falacia. Como lo más ordinario es que hayan identificado al bien (que no es una propiedad física o natural) con propiedades físicas o naturales, como la sensación de placer o el ser deseado [de hecho], Moore decidió llamar a esa falacia, "falacia naturalista" (\$§ 6,10,11,12). Sin embargo, él no pensaba que fuera exclusiva de los utilitaristas (Bentham) o de los spencerianos o de los psicologistas (Mill) o de los sociologistas (Clifford), sino que la atribuye también a ciertos pensadores, como Kant y Hegel, que identifican el bien con una cosa diferente, aunque no se trate de una realidad natural, sino de un rasgo que exis- 
te en un mundo suprasensible y real, como la rectitud de la voluntad o el "Reino de los Fines", por ejemplo ( $\S 25,26,66-67,76-77,83,84,85,108)$.

Moore abandona con claridad el nominalismo porque postula que el bien es verdaderamente una propiedad de los objetos o cosas cuya captación pertenece al intelecto ( $\S 79-80)$. Por eso le parece obvio que el voluntarismo y formalismo kantianos tienen que ser falsos: la voluntad por sí sola no puede constituir lo bueno ni fundar la buena acción o la obligación moral (§§ 75-76). En cambio, Moore rescata de Kant la distinción entre voliciones y pasiones, apartándose en ello de Hume ( $\S 78$ y ss.). La profundidad de las intuiciones y la energía con que se despliegan debería haber convertido a este notable autor en el inicio de una restauración de la ética realista en la corriente principal de la tradición filosófica de habla inglesa.

Sin embargo, algunos rasgos de su obra, que discutiremos en los artículos siguientes, impidieron que se convirtiera en la susodicha restauración. Comencemos el examen de esos rasgos con la crítica colateral, aunque explícita, que dirigen a Aristóteles los Principia Ethica.

\section{Artículo 1. Si Aristóteles incurrió en la falacia naturalista}

Y parece que sí.

[Objeción:]

1. En efecto, Aristóteles identificó en la Ética a Nicómaco el bien con la theoría $(\S 106)$.

[Cuerpo de la respuesta:]

Respondo que Aristóteles distinguió muy claramente entre el bien humano y el bien en general ${ }^{1}$ y limitó el objeto de la ética a la discusión del bien humano. El estudio del bien en general no pertenece a la ética, sino a la filosofía primera y a la filosofía natural. Moore no puede percibir que su lectura de Aristóteles es errada porque no conoce a fondo la filosofía aristotélica y porque, en cambio, atribuye el conocimiento del bien exclusivamente a la ética. En esto es un hijo de la tradición empirista que, al menos desde Locke, y a causa del nominalismo, incluye la consideración del bien en general dentro del estudio de las pasiones humanas cuya raíz sería la pasión del placer $^{2}$.

Aun en lo que se refiere al bien humano, ciertamente Aristóteles no reduce el bien moral a la contemplación o a las virtudes dianoéticas, sino que considera también a las acciones conformes a las virtudes éticas como parte importante de ese bien. Por si fuera poco, Aristóteles señala que además del bien moral exis-

\footnotetext{
1 Cfr. Ética a Nicómaco I 6, 1096a11-1097a14.

2 Lo hizo en Locke, J., Ensayos sobre el entendimiento humano, Buenos Aires, Fondo de Cultura Económica,1956, libro II, capítulos 20-21.
} 
ten los bienes a los que tienden las diversas técnicas y los bienes naturales y de fortuna. Con esto queda patente la respuesta a la objeción.

\section{Artículo 2. Si el bien puede identificarse con el ser y si, en consecuencia, el conocimiento de estas dos propiedades o realidades puede pertenecer al mismo tipo de acto del entendimiento}

Y parece que no.

[Objeciones:]

1. En efecto, como sostiene Moore, "bien" tiene que consistir en una propiedad diferente del "ser", conforme al argumento conocido como de la pregunta todavía abierta, que él formula así en este contexto: "De cualquier cosa que hayamos probado que existe [...] sigue habiendo todavía una pregunta distinta y diferente acerca de si lo que así existe es bueno [...]. Afirmar una cosa clara y obviamente no es lo mismo que afirmar la otra. Entendemos qué queremos decir cuando preguntamos: ¿es esto, que existe, o que necesariamente existe, después de todo, bueno? Y percibimos que estamos planteando una pregunta que todavía no se ha respondido. Ante el hecho de esta percepción directa de que las dos cuestiones son distintas, ninguna prueba de que ellas deban ser idénticas puede tener el menor valor" ( $\$ 74)$.

2. El argumento anterior puede reforzarse con una consideración adicional. Quienes sostienen que el bien tiene que existir no perciben que las proposiciones pueden dividirse en tres grandes tipos: las de experiencia, como que yo estoy aquí, escribiendo este artículo; las científicas, como que $2+2=4$; y las relativas al bien. Los filósofos empiristas han pensado equivocadamente que una proposición no puede ser condicionalmente verdadera, como lo son de ordinario las proposiciones científicas, sino que, la suma, por ejemplo, significaría que, hasta ahora, en todos los casos en que dos cosas de experiencia se han puesto junto a otras dos cosas de experiencia han resultado cuatro cosas de experiencia. Reducen, pues, todas las proposiciones a proposiciones de experiencia. Los "metafísicos", tal como los entiende Moore, es decir, los pensadores de la tradición platónica-agustinista, entre los que se cuentan Leibniz, Kant o Bradley, tienen el mérito de abrir espacio para entender las proposiciones de un modo un poco más amplio: la suma puede ser verdad aunque no signifique que siempre en la experiencia dos cosas añadidas a otras dos han dado lugar a cuatro. De manera análoga, las proposiciones "esto sería bueno, si existiera" o "esto es bueno" son interpretadas por los empiristas como "esto ha existido y ha sido deseado" o "esto es deseado de hecho". Los "metafísicos", en cambio, abren nuevamente lugar para proposiciones que no sean proposiciones de experiencia en lo que se refiere al bien. Pero, incurren en otro error: no entienden las 
proposiciones científicas y éticas en el sentido que realmente tienen, un sentido condicional o un sentido propiamente ético. Ésta es la causa por la que los metafísicos piensan que, para que las proposiciones del segundo y tercer tipo sean verdaderas, tiene que existir alguna clase de Realidad suprasensible a la que correspondan ellas o sus predicados, entre los que se cuenta el "bien". Esa Realidad consistiría en un estado de la mente de Dios, según Leibniz; o en un estado de la razón humana, según Kant; o en algo existente en algún estado, según Bradley. (§§ 71-74).

3. Además, de acuerdo con Hume, las percepciones se dividen en dos grandes clases, ya sean "ideas" ya sean "impresiones" (que incluyen, por ejemplo, las pasiones del amor y del odio). Los juicios sobre lo que es bueno o malo son "impresiones", no ideas. Pero solamente los juicios sobre las ideas pueden ser verdaderos o falsos, pues la verdad y falsedad residen en ciertas relaciones entre las ideas [nótese bien, las ideas, no las impresiones] o entre éstas y la existencias reales o los hechos ["matters of fact"]. Algo que juzgamos malo, como un homicidio, por ejemplo, si se examina con cuidado, no revelará en su estructura objetiva nada que permita decir que considerarlo "malo" sea verdadero o falso. Esa etiqueta designa el sentimiento que la acción despierta en el pecho del observador, más bien que algo que se encuentre en la realidad. Como los colores o el calor, lo bueno o lo malo no son sino percepciones que se encuentran en la mente, no en los objetos ${ }^{3}$.

En contra está lo que dice el Angélico, que el bien es una noción trascendental, que se puede convertir con el ser 4 .

[Cuerpo de la respuesta:]

Respondo con Peter Simpson ${ }^{5}$ que el bien se dice en muchos sentidos, pero en uno de ellos es una noción trascendental. Ser una noción trascendental significa que es intercambiable con la de ser. Pero, aunque sea intercambiable, no es idéntica, porque aquélla añade una razón intencional a ésta. -En el caso del bien, la de contener el ser lo que puede llenar el deseo de la voluntad o simplemente merecer su aprobación o ser capaz de causar su gozo (como se da en las realidades inmóviles, divinas o angélicas). Ser una noción trascendental también significa que se da en todas las categorías sin ser ella misma una categoría. Es metagenérica y, por tanto, no se puede definir 6 . Además, uno puede entender

\footnotetext{
${ }^{3}$ Cfr. Hume, D., Treatise of Human Nature, Oxford, Oxford University Press, 1896, Libro III, Parte I, Sección I. También, Libro II, Parte III, Sección III.

${ }_{4}^{4}$ De Veritate qq. 1 , a. $1 ; 21$, a. 1.

5 Simpson, P., "Saint Thomas and the Naturalistic Fallacy", The Thomist 51 (1984), pp. 51-69.

${ }^{6}$ Moore observa, como nosotros, que el bien no se puede definir, pero se funda en una razón errada. Moore afirma, en efecto, que el bien no es definible porque es una noción simple, y, de acuerdo con la teoría empirista de la definición, se puede definir una noción solamente cuando se compone de
} 
cada cosa por medio de una noción categorial, como la de "alimento", pongamos por caso, o con una noción trascendental, la de bien, que no añade nada real a lo mentado con "alimento", sino una razón diferente. Ser, ser bueno y ser alimento, en el alimento, son lo mismo, según el sujeto y según la razón real significada, pero no según la razón intencional. Este no ser lo mismo según la razón intencional es lo que explica lo que la tradición analítica ha conocido como la "supervenience of the good", es decir, que el bien parece añadir una formalidad a las formalidades que comprendemos cuando describimos una cosa con predicados genéricos o específicos. -Como cuando describimos una "fresa" como "grande", "roja", "jugosa", "dulce", o como "buena".

[Respuesta a las objeciones:]

Ad $1 \mathrm{~m}$. A la primera objeción se puede responder que es reflejo de una falta de análisis ${ }^{7}$, que se traduce en una grave deficiencia lógica, que procede de la tradición empirista. Si las ideas o conceptos generales son o simples o compuestos, y los simples son sensaciones o percepciones actuales, como sostuvo Locke, parecería que toda idea o concepto simple consiste en una sensación o percepción de una cosa o de una propiedad diferentes a toda otra cosa o propiedad. Es ésta la razón por la que Moore supone que la idea de "bien" debe referirse a una propiedad diferente de aquélla a la que se refiere la idea de "ser". Pero un análisis cuidadoso de la experiencia humana revela sin mucha dificultad que los conceptos no son percepciones, como es fácil probar porque un niño de un año tiene percepciones de los diversos colores pero no tiene los conceptos de los colores. Además, no siempre los diferentes conceptos o nociones inteligibles corresponden a diferentes propiedades reales de las cosas. Los sustantivos, adjetivos y verbos de ordinario tienen un significado que es un concepto que constituye una semejanza natural de una razón real de las cosas. Dos conceptos pueden referirse a la misma cosa pero tener significados distintos por ser semejanzas de razones reales diferentes de la misma cosa, como "gato" y "blanco". Ahora bien, hay conceptos o nociones que son semejanza de la misma razón real, pero desde puntos de vista diferentes. Eso es lo que ocurre con las nociones trascendentales, que significan la misma realidad y la misma razón real desde puntos de vista diferentes y, por tanto, significan razones intencionales diferentes. Entonces, aunque se refieran al mismo sujeto y bajo la misma razón real, pueden referirse a ella bajo diversos aspectos y tener diverso significado. Esta diversidad no siempre exige la multiplicación de razones reales. Por lo tanto, afirmar que "algo es" no equivale a afirmar que "algo es bueno", pero

muchas propiedades o cualidades que pueden pensarse o percibirse separadamente, y que se pueden enumerar $(\S \S 6,8,13)$.

7 Moore no percibe que ha llegado a un callejón sin salida, sino que pasa a concebir "aquello que debe existir", el "bien en sí" que debe promover la acción humana, como algo irreal, ficcional, como una utopía o un ideal. Aquí ya se desliza sin percatarse de ello al terreno de la ideología (§ 71). 
no implica que "bien" tenga que significar otra razón real u otra propiedad predicable verdaderamente ${ }^{8}$.

Ad $2 \mathrm{~m}$. A la segunda objeción se puede responder que aunque las proposiciones éticas sean diferentes tanto de las proposiciones que Moore llama "empíricas" como de las que llama "científicas", lo son por la referencia del bien a la voluntad que, como hemos visto, no añade a la noción de "ser" ninguna propiedad predicable verdaderamente. Por extraño que pueda parecer, Moore ha incurrido en el tipo de error que él achaca a los "metafísicos" de la tradición platónicoagustinista: suponer que debe haber alguna propiedad particular (en su caso "no existente") que corresponda a las palabras que se predican con verdad de un sujeto.

Ad 3m. A la tercera objeción se puede responder que la metafísica empirista se equivoca al identificar los conceptos o ideas con percepciones, como se ha dicho. Hume, además, se equivoca al incluir entre las "percepciones", que son actos cognoscitivos, otros actos que claramente son apetitivos, como las pasiones del amor o el odio. Por último se equivoca cuando sostiene que la captación de lo bueno o lo malo no es otra cosa que una reificación de una impresión. El único motivo que puede dar verosimilitud a esa tesis es que las nociones de "bueno" y "malo", como hemos visto, contienen una referencia a la voluntad, que él identifica con las pasiones. Ya se ha mostrado suficientemente que esa referencia que en efecto entra en la noción de "bien" (y, por tanto, en la de "mal") no implica que "bien" no signifique una razón real.

\section{Artículo 3. Si la máxima "obra de acuerdo con la naturaleza" incurre en la falacia naturalista}

Y parece que sí.

[Objeción:]

1. En efecto, dicha máxima equivale a identificar con el bien que debe promover la moral cosas que se siguen de las leyes establecidas por las ciencias naturales o cosas que son simplemente "normales" porque ocurren generalmente. Pero, como sostiene G. E. Moore, es obvio (a) que las conclusiones de la ciencia nada tienen que ver con lo que sea moral, y (b) que muchas cosas excelentes son "anormales" desde el punto de vista de la ciencia médico-psiquiátrica, como el genio de Sócrates y el de Shakespeare. Por tanto, no todo lo bueno es "normal" (§ 27).

\footnotetext{
8 Recuérdese, además, que "bueno" se entiende de muchas maneras: existe el "bien metafísico" y el "bien moral"; y ambos se dividen en el "bien honesto", el "bien útil" y el "bien deleitable". Sólo el primer tipo puede identificarse, en uno de sus sub-sentidos, con el ser.
} 
En contra se halla que Platón enseña en el libro VIII de las Leyes (838e) lo siguiente: "[...] tengo una traza en favor de esta ley que ordena usar de la unión procreadora en conformidad con la naturaleza [...]".

[Cuerpo de la respuesta:]

Respondo que el Derecho natural clásico nació en lucha con una concepción semejante a la presupuesta en la objeción, es decir, la concepción sofística del Derecho natural. Por eso pudieron los clásicos aclarar muy bien el sentido en que se toma "naturaleza" cuando se habla, por ejemplo, de lo que requieren las virtudes de la moderación o de la castidad. Se trata, como ha señalado Carlos Massini", de un sentido metafísico que es, por ello, (a) distinto tanto de "lo que ocurre generalmente" como de los resultados de la investigación de las ciencias particulares, y (b) previo a estos últimos.

Lo que da origen a la objeción de Moore es que piensa que todo posible estudio de las realidades u "objetos" que existen, han existido o existirán en el tiempo pertenece a las ciencias físicas o naturales, a las que llama también "ciencias empíricas o positivas", y entre las que incluye a la psicología (§§ 25-26). De aquí es de donde saca la idea de que la naturaleza no puede dar ningún criterio moral, pues "naturaleza" no podría significar otra cosa que o bien lo que estudian las ciencias físicas, o bien lo "normal". En este punto, entonces, aunque el propósito mooriano es laudable, sus presupuestos y su método no lo son. En efecto, (a) Moore no puede concebir otro modo de determinar lo que es conforme a la naturaleza sino de acuerdo con una ciencia natural, que, según él, viene a ser lo mismo que definirlo como lo "normal". No puede ver que los conceptos implicados en la consideración del genio de Sócrates o de Shakespeare nada tienen que ver con la salud que es objeto de la medicina, de tal modo que cualquier médico que hable de esas materias (excepto quizá para determinar los correlatos fisiológicos o anatómicos) está traspasando los límites de su disciplina. Y (b) no puede concebir Moore, tampoco, que, acerca de las realidades de nuestra experiencia, exista una reflexión disciplinada, no de simple "sentido común", que no constituya una actividad científico-natural.

[Respuesta a la objeción:]

Ad 1m. A la objeción puede responderse que la ciencia natural presupone conceptos y principios que ella no prueba, tomados tanto de la matemática como de la metafísica. No es ciencia primera la ciencia natural, tampoco en lo que se refiere al discurso referido a las realidades de nuestra experiencia. Si es cierto que la ciencia natural puede no considerar temáticamente la unidad substancial de las realidades que considera, ni la causa de tal unidad, ni la ordenación teleológica de las partes de esa realidad al bien del todo o la finalidad que se encie-

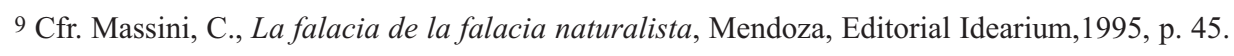


rra en la acción de los poderes naturales, si todo esto es cierto, no es menos cierto que la metafísica sí considera todos estos aspectos de lo real, que lo hace disciplinadamente y que, por ello, puede dar lugar a una filosofía natural o una antropología filosófica, y puede también esclarecer imprescindibles prolegómenos de la ética10. La máxima que ordena "obrar conforme a la naturaleza" no debe entenderse como "obrar conforme a lo que enseñan las diversas ciencias naturales", porque ellas no enseñan nada en relación con cómo debe obrarse11. Debe entenderse, en cambio, como un consejo de respetar el orden de la naturaleza humana entendida en sentido de canon, que poco tiene que ver con lo "normal", y que se distingue claramente de la "naturaleza" tomada en el sentido de aquello que está sometido a la mera dominación técnica12.

En este punto convendría considerar la crítica de Germain Grisez y John Finnis a lo que ellos han denominado "el argumento de la facultad pervertida", pero me lo impiden las limitaciones de espacio que son apropiadas para un escrito como éste.

\section{David Hume e Immanuel Kant}

David Hume constituye uno de los puntos de inflexión en una de las tradiciones filosóficas vivas en nuestro tiempo: la tradición ilustrada. Dentro de ella, sus argumentos jugaron un papel importante en el curso que han tomado la metafísica y la ética. Muchos de esos argumentos, sin embargo, si se examinan bien, tienen fuerza si, y sólo si, se acepta de antemano el empirismo y sus doctrinas básicas. Ya mencionamos una de esas doctrinas: Todas las ideas simples son percepciones meramente sensoriales. Otra doctrina que se sigue de la anterior y que tiene relevancia en este contexto es la reducción de la voluntad a la pasión dominante, que tiene como consecuencia la reducción de la razón al estado de sierva de las pasiones 13 .

\footnotetext{
10 Finnis, J., Natural Law and Natural Rights, Oxford, Oxford University Press, 2011, tiene toda la razón en que la ética existe antes que la metafísica. Pero él también observa que hay realidades o dimensiones de la realidad sobre las que toca a la metafísica reflexionar disciplinadamente y que la ética presupone. Una vez que ha aparecido la metafísica, una desviación de ésta puede oscurecer esos presupuestos de la ética y requerir una nueva aclaración metafísica. Tal es el la tarea que estamos realizando en este momento.

11 La medicina, por ejemplo, puede prescribir conductas, pero no en cuanto ciencia natural, sino en cuanto arte de la salud.

12 Sobre este tema y sobre esta distinción he hablado largamente en “¿Por qué tiene tantas dificultades la razón natural en nuestra época para reconocer las doctrinas centrales de la encíclica Humanae Vitae?", en Razón y tradición. Estudios en honor de Juan Antonio Widow, Santiago, Editorial Globo, 2011, pp. 353-377.

13 Cfr. Tratado sobre la naturaleza humana. Libro II, Parte III, Sección III. También, Libro III, Parte I, Sección I.
} 
Hay, con todo, dos observaciones de Hume conectadas con la cuestión que examinamos hoy que merecen una discusión detenida y que incluiremos en los artículos siguientes.

Immanuel Kant, por su parte, acepta de Hume todo lo que se refiere a la fuerza de la experiencia para darnos conocimiento del bien inteligible. Es decir, piensa, como Hume, que de los objetos de experiencia no puede provenir ningún criterio moral verdadero (ver artículo 2, objeción $3^{\mathrm{a}}$ ). A diferencia de Hume, en cambio, sostiene que la voluntad no es reductible a las pasiones. Estos dos aspectos conjugados van a dar lugar a los principios fundamentales de la moral kantiana. Sin embargo, el pensador de Königsberg acabará separándose de esos principios cuando se vea precisado a proponer máximas morales con contenido.

Sin más preámbulos, examinemos los principales problemas que podrían plantear al jusnaturalismo clásico las doctrinas de estos dos autores, así como los principales aportes que podrían rescatarse de sus obras en el contexto presente.

\section{Artículo 4. Si de la consideración del "ser" solo, o del "bien", se puede extraer toda la moral}

Y parece que sí.

[Objeción:]

1. En efecto, de acuerdo con Clarke, según lo expone Hume, la moral no es otra cosa que un conjunto de eternas correlaciones apropiadas o inapropiadas entre realidades ${ }^{14}$.

[Respuesta:]

A esto debe responderse, con David Hume, que no bastan esas correlaciones "objetivas" para dar lugar a la moral, sino que es preciso que ellas se vinculen a un agente moral y a su apetito [racional]. Esta observación de Hume requiere de una aclaración que se discutirá más tarde: la razón, para hallar la verdad práctica, debe considerar lo que haría el apetito recto, pues éste es la causa agente última del obrar bien. Sin embargo, puede ocurrir que una razón que delibere bien no sea secundada por el apetito, de donde se ve que no es éste la regla de la razón práctica.

\section{Artículo 5. Si el "ser" o el "bien real" puede ser fuente alguna de las máxi- mas morales}

Y parece que no.

14 Cfr. Tratado sobre la naturaleza humana. Libro III, Parte I, Sección I. Que el autor criticado por Hume sea Clarke, es algo que muestra John Finnis en su obra Natural Law and Natural Rights, Oxford, Oxford University Press, 1980, pp. 33-48; y 2011 (segunda edición), Capítulo 2, secciones 56, pp. 36-48. 


\section{[Objeciones:]}

1. En efecto, la famosa ley de Hume establece que un razonamiento moral incurre en una falacia si concluye una proposición de "deber ser" a partir de premisas cuyas cópulas hablan sólo del "ser"15.

2. Además, Kant enseñó que "por desemejantes que sean las concepciones de los objetos, sean ellas propias de la comprensión o aun de la razón en lugar de los sentidos, la sensación de placer por la cual ellos constituyen el fundamento determinante de la voluntad (puesto que es el agrado y el disfrute que uno espera del objeto lo que mueve la actividad hacia su producción) es siempre la misma. Esta mismidad no reside meramente en el hecho de que las sensaciones de placer puedan ser conocidas sólo empíricamente, sino aún más en el hecho de que la sensación de placer siempre afecta una y la misma fuerza vital que se manifiesta en la facultad del deseo, y a este respecto una causa determinante puede diferir de otra sólo en grado"16. Como, sin embargo, Kant postula la voluntad como diferente de las pasiones, tiene que postular también que "una voluntad libre debe encontrar su fundamento de determinación en la ley, pero con independencia del material [o contenido] de la ley"17. Por ello, el precepto ético debe ser meramente formal18, y reza así: "obra de tal manera que tu regla de conducta pueda ser adoptada como una ley por todos los seres racionales" 19 . En contra, el Angélico enseña que el ser del agente y la realidad del bien a que se refiere la acción son los dos principios primeros de la moral 20 .

[Cuerpo de la respuesta:]

Respondo que una moral realista sabe, como enseña John Finnis, que el primer principio práctico no se deriva de nada ${ }^{21}$. Tal principio se formula correctamente así: "ha de hacerse el bien conveniente aprehendido". Como hemos visto,

\footnotetext{
15 Aun este argumento humeano es circular. Lo que quiere decir el pensador escocés es sencillamente que la facultad cuyo objeto son las ideas y la relación de éstas con los hechos o entre sí, la razón, sólo puede conocer el "ser"; mientras el "deber ser" es un asunto de "impresiones", que constituyen el otro tipo de "percepciones" según el empirismo humeano, y que se encuentran, por definición de ese mismísimo empirismo, fuera del objeto de la razón.

16 Parte I, Libro I, Capítulo 1, Teorema 2, Observación I, p. 42 de la edición original.

17 Problema II, Parte I, Libro I, Capítulo I, p. 140 (p. 52 de la edición original).

18 Observación a la Ley fundamental de la razón pura práctica, p. 143 (p. 56 de la edición original): "En orden a comprender esta ley, [la ley fundamental de la razón pura práctica] uno debe notar que no es un hecho empírico, sino el solo hecho de la razón pura, que se proclama a sí mismo como originariamente legislativo (sic volo, sic iubeo)". Hans Kelsen no hace sino seguir a Kant en este punto. Cfr. Teoría pura del Derecho, Valladolid, Editorial Trotta, 2011 (traducción de la primera edición de 1934), $\S 8$.

19 P. 54 de la edición original.

20 Cfr. Super Sent., lib. 2 d. 41 q. 1 a. 1 co.; Suma teológica I-II, q. 21 a. 1 co.

21 Cfr. 1980, pp. 33-34. Citado por Carlos Massini, 1995, pp. 61-62.
} 
"bien" es una noción trascendental, convertible con la de "ser", sobre la cual tenemos conocimiento teórico. Cuando se dice "conveniente" se incluye una proporción con el agente que se puede conocer tanto teórica como prácticamente. Por ejemplo, si digo aquí y ahora que "un abogado sin conocimientos de primeros auxilios no debe levantar del suelo y llevar a una clínica a una persona atropellada con posible daño vertebral", esa proposición es teórica. Pero si yo me encuentro en esa situación y, al deliberar, llego a ese juicio, he llegado al conocimiento de una verdad práctica. El primer principio práctico, eficazmente activo en todas las acciones moralmente buenas, incluye una referencia al apetito: "ha de hacerse"22. Como hemos visto, sin esa relación al apetito no puede haber moralidad. Por ello, también el juicio con el que acaba la deliberación 23 incluye una referencia al apetito recto: "esto es lo que he de hacer". Por tanto, el orden real, existente, es decir, el orden del ser o la verdad sobre el bien es el núcleo de la consideración moral e incluye el apetito del agente como un elemento de ese orden.

[Respuesta a las objeciones:]

Ad 1m. A la primera objeción puede responderse, por tanto, que en toda deliberación entra como una premisa explícita o implícita el primer principio práctico que incluye la consideración del apetito y de su orden a la acción debida. También incluye la consideración del bien, que, como hemos visto en el artículo 2 , es consideración sobre el ser bajo una razón intencional distinta.

Ad 2m. Respecto de la segunda objeción debe decirse con John Stuart Mill que sin referencia a los objetos nada garantiza que no puedan ponerse de acuerdo todos los sujetos racionales en establecer una ley que adolezca de locura ${ }^{24}$. Además, el propio Kant contradice los supuestos principios que describimos en la objeción cuando establece máximas morales más o menos sensatas en la Metafísica de las costumbres ${ }^{25}$. El primer principio de la moral, como acaba de

\footnotetext{
22 Debo a una observación de Marco Antonio Navarro una precisión en la manera de formular el primer principio práctico. Él tomó su observación, según me dijo, de una obra de Ana Marta González. ${ }^{23}$ Cfr. Carlos A. Casanova. "Una reconsideración del De Motu Animalium y el silogismo práctico", en Pensamiento, Vol. 65, No. 44 (2009), pp. 339-353.

24 Cfr. Utilitarianism. Capítulo 1, p. 165-166; y capítulo 5, p. 216. En: Plamenatz, John. The English Utilitarians, Oxford, Basil Blakcwell, 1949, pp. 161-228.

${ }^{25}$ Lo que ocurre en esta obra es lo que había señalado de modo general Etienne Gilson en El realismo metódico. Es decir, que por medio de una vuelta a las cosas se llena de "substancia" los principios supuestamente formales, se llena de contenido realista la ética (cfr. El realismo metódico, Madrid, Ediciones Rialp, 1974, p. 122), En efecto, Kant no puede quedarse con el imperativo categórico puramente formal de la Crítica de la razón práctica, sino que tiene que llenarlo de contenido. ¿Cómo lo hace? Por medio de la siguiente declaración: “[...] una metafísica de las costumbres no puede fundamentarse en la antropología, pero, sin embargo, puede aplicarse a ella" (p. 217 de la edición de la Academia de Berlín, según la traducción de Adela Cortina y Jesús Conill Sancho. Editorial Tecnos,
} 
decirse, no se puede probar. Sólo se puede defender por medio de argumentos ad hominem que hagan patentes ante los ojos de los contradictores que su rechazo lleva a consecuencias inaceptables para ellos mismos. Por eso es relevante mostrar que el mismo Kant no pudo atenerse a las afirmaciones a que había llegado en la Crítica de la razón práctica en contradicción con el primer principio $^{26}$. Por otra parte, una vez que se abandona el nominalismo, que postula que no podemos conocer en los objetos de experiencia bienes que sean dignos del amor de la voluntad o que no podemos jerarquizar los bienes sino en relación con la facultad de sentir o con el placer que nos producen, se derrumba la razón que aduce Kant para sostener que del ser no se sigue criterio alguno sobre el deber ser. Ése es, por cierto, uno de los méritos de la obra de G. E. Moore, haber abandonado el nominalismo, que es la razón por la que critica sólidamente el voluntarismo moral kantiano.

Sin embargo, presiona más el problema porque algunos sostienen que la razón por la que sabemos que una acción concreta es mala reside en ciertos principios universales que se aplican a las cosas que existen, pero que no proceden de ellas. A esto debe responderse que esos "principios" de la sindéresis no son formales, sino que tienen un contenido que significa bienes reales. La regla de oro, por ejemplo, presupone que sabemos lo que es un daño y lo que es un ser humano y que reconocemos a un individuo como ser humano y una acción concreta como dañosa. Es decir, los principios son proposiciones y ninguna proposición puede aplicarse a lo concreto si no se captan en lo concreto las rationes significadas por los términos. De modo que, si las proposiciones pueden aplicarse a lo concreto es porque se reconoce en esto lo que se significa en aquéllas. Por este motivo, si

Madrid, 2008). Además, Kant presupone que se puede conocer a los otros en cuanto otros y reconocer deberes respecto de ellos. En este punto incurre en el mismo problema que en la Fundamentación de la metafísica de las costumbres, cuando en la segunda formulación del imperativo categórico sostiene que debe tratarse a la humanidad, en sí y en los otros, como un fin en sí mismo y no como un mero medio. -Porque allí no se establece un principio meramente formal. En efecto, captar el qué es de algo supone captarlo como ser. Esto, a su vez, supone captarlo como otro, distinto de mí. Edmund Husserl, igual que Kant, aceptaba esto sólo de los otros "sujetos trascendentales", pero, como bien observó Edith Stein, no hay razón alguna para aceptar la alteridad de los otros sujetos si no hay razón para aceptar la alteridad del ser sensible en general. En efecto, los otros sujetos se nos dan en sus manifestaciones sensibles. (Cfr. Potenz und Akt. Studien zu einer Philosophie des Seins, ASW 18, 1998, p. 256. Citado por Teruel, Pedro Jesús. "Edith Stein y el problema de la Konstitution", pp. 91-92. Diálogo filosófico 58 [2004], pp. 79-96). Esto se aplica también a la captación relevante a la moral. Si no puedo captar a los otros hombres en cuanto seres dignos de un cierto trato moral, ni siquiera puedo postular la "constitución" de intersubjetividad alguna.

26 Tampoco Kelsen pudo: al final, la determinación del deber requiere de la constatación de ciertos hechos relativos, por ejemplo, a cuál sea la Constitución vigente. Max Silva ha hecho una observación análoga, con particular fuerza, en su estudio sobre Norberto Bobbio: cfr. Derecho, poder y valores. Una visión crítica del pensamiento de Norberto Bobbio, Granada, Editorial Comares, 2008, pp. 280 y 398. 
un principio se puede aplicar a lo concreto también pudo tomarse de lo concreto. Es verdad que los primeros principios de la moral son naturales, pero esto no excluye que vengan de la experiencia en sentido clásico (diferente del sentido humeano), porque en ella llegamos a concebir sus términos y captar las formalidades reales de las que aquéllos son semejanzas. Es por esto que Aristóteles enseña en el libro VI de la Ética a Nicómaco que la deliberación se mueve entre el intelecto de lo universal y el intelecto de lo particular, pero que el intelecto de lo universal procede de la experiencia de lo particular (cfr. 11, 1143a35-1143b5). Santo Tomás lo sigue en este punto (cfr. De Veritate q. 10, a. 6).

\section{Artículo 6. Si la razón práctica está embebida en el apetito}

Y parece que sí.

[Objeciones:]

1. En efecto, la verdad práctica es la conformidad con el apetito recto. De donde se sigue que la deliberación busca ajustarse al apetito recto como a su medida, y no a la naturaleza de las cosas.

2. Por otra parte, según enseña Elizabeth Anscombe, la conclusión de la deliberación es lo elegido 27 . Luego, no puede la razón práctica llegar a una conclusión verdadera sin la concurrencia del apetito recto.

3. Además, para que una consideración sea moral debe contener una referencia al apetito, como hemos visto en el artículo 4. De aquí se sigue lo que dice Peter Simpson: "el razonar práctico es [...] razonar al servicio del deseo".

4. Más todavía, la prudencia, que es la virtud de la razón práctica, se refiere a los medios para alcanzar el fin deseado por la virtud moral. Luego, la razón práctica es abarcada por la virtud moral.

En contra está que Aristóteles y el Angélico enseñan que algunos tipos de incontinentes pueden llegar en su deliberación a la conclusión correcta, a un juicio verdadero, a pesar de no contar con el apetito recto 28 .

[Cuerpo de la respuesta:]

Respondo que, como se deriva de lo que hemos estudiado en el artículo 5, la verdad práctica consiste en la conformidad del juicio en que concluye la deliberación con la acción realmente debida. El carácter de "debida" de la acción no se sigue de que la exija el apetito, pues el apetito mismo puede ser recto o torcido. Precisamente la "rectitud" del apetito depende de que exista la proporción

27 Cfr. Intention, Oxford, Oxford University Press, 1958, pp. 60-61. Citada por Martha Nussbaum. "Essay 4," p. 186. En: Aristotle's De Motu Animalium, Princeton, Princeton University Press, 1978, pp. $165-220$.

28 Cfr. Ética a Nicómaco VII 3, 1147b9-12. 
realmente debida entre el agente y los bienes que desea y elige. La proporción, a su vez, depende de la naturaleza y disposiciones del agente, de los bienes que se encuentren en la situación en que ha de obrar y de la jerarquía de los mismos, de todas las circunstancias y de la ordenación al bien común político o cósmico. Todo esto es materia que capta e investiga el intelecto o la razón humana ${ }^{29}$, porque, tal como lo entendió Peter Simpson, la intelección del bien conveniente es la causa final universal de las acciones humanas, mientras la voluntad es la causa eficiente universal ${ }^{30}$. Un hombre que no esté del todo corrompido tiene la posibilidad metafísica, por ello, de captar el bien práctico que él no ama lo bastante como para realizarlo. Y ningún hombre está por entero corrompido: por eso no puede eliminarse del todo el primer principio práctico o moral, por lo que siempre puede éste constituir, en esta vida, un terreno común para la discusión moral.

[Respuesta a las objeciones:]

Ad 1m. A la primera objeción ha de responderse que la expresión "conformidad con el apetito recto" es, en parte, lo que Max Weber y Eric Voegelin han llamado un "concepto tipo" 31 . La tradición jurídica romanista establece un concepto semejante cuando, para determinar si un daño ha sido causado con culpa, se pregunta si el agente actuó con la diligencia que se puede exigir a un "buen padre de familia". Es decir, la razón que delibera bien tiene que encontrar lo que elegiría el apetito recto, y puede hacerlo aun cuando el agente que delibera no tenga él mismo un apetito recto. Un juez puede saber cuál sería la decisión justa en un caso, aun si él mismo es inicuo, siempre que, precisamente, investigue "qué es justo en este caso", siempre que presuponga que hay que buscar lo que desearía el apetito recto. Claro que en el caso de la verdad práctica su relación con el apetito recto es más intensa que la relación entre el agente y el concepto del buen padre de familia en el caso de los daños derivados de culpa, porque en el de de la verdad práctica el juicio es verdadero si determina lo que es proporcionado a lo que desearía el agente, si fuera bueno.

29 Cfr. Suma teológica II-II, q. 47, a. 6. Cuando los consecuencialistas dicen que las normas morales tal como las concibe el jusnaturalismo clásico son tautológicas porque lo que prohíben no es matar, sino el "homicidio", que incluye ya la deformidad, no tienen razón. Pero no la tienen precisamente porque los tipos de acciones malas o buenas surgen de la experiencia, donde el intelecto percibe la deformidad o falta de proporción de una conducta, en relación con todo el contexto en que se enmarca. Esta prioridad de lo concreto es lo que convierte a la ética en una disciplina tópica o dialéctica.

30 Esto implica, sin embargo, que la ordenación inicial de la voluntad es obra del Autor de nuestra naturaleza, pues, de otra manera, no podría moverse el intelecto a realizar su primer acto. Cfr. el comentario al De Trinitate de Boecio, Proemium, q. 1, a. 3, ad 4m.

31 Cfr., por ejemplo, "The Meaning of Ethical Neutrality in Sociology and Economics", pp. 41-44. (En: Max Weber on the Methodology of the Social Sciences, The Free Press of Glencoe, Illinois, 1949, pp. 1-47). 
Ad 2m. A la segunda objeción ha de responderse que la conclusión de la deliberación no es "lo elegido" como sostiene Elizabeth Anscombe, sino "lo elegible" 32 . Por eso se puede deliberar bien y no elegir lo deliberado. En este caso, por supuesto, la razón práctica no tiene su virtud propia, que es la prudencia, aunque razone bien, porque le falta el imperio.

Ad $3 \mathrm{~m}$. A la tercera objeción se debe responder que el razonar al servicio del deseo puede entenderse ya sea como razonar al servicio del deseo más fundamental de la voluntad, que es el deseo del bien conveniente; ya sea como razonar al servicio del apetito recto entendido como concepto tipo, según se ha explicado. En ninguno de los dos sentidos se significa que el intelecto quede embebido en el apetito, sino que se abre a la realidad, como se ha dicho.

Ad $4 \mathrm{~m}$. A la cuarta objeción ha de responderse que la prudencia no se refiere sólo a los "medios" para alcanzar el fin perseguido por el apetito recto, sino, a "aquellas cosas que se ordenan a ese fin". Pero entre esas cosas se cuenta de modo principal, precisamente, la determinación de aquello en lo que consista el fin aquí y ahora, como se ve en el ejemplo del juez inicuo que se ha dado en la respuesta a la primera objeción: el objeto de su conocimiento, cuando presupone que busca lo que desearía el apetito recto, reside en determinar en qué consista la justicia en el caso concreto, es decir, en qué consista el medio de la virtud en el caso concreto. Es por este motivo que Aristóteles enseña que la virtud sin prudencia sería ciega ${ }^{33}$, que la prudencia es el auriga de todas las virtudes ${ }^{34}$ y que Sócrates tenía cierta razón, porque, aunque no puede reducirse la virtud moral a prudencia, no hay verdadera virtud moral sin prudencia ${ }^{35}$. Santo Tomás lo sigue en todo esto, y aclara que lo que es propio de la prudencia es determinar el "medio" entre dos extremos en que consiste la acción virtuosa, lo cual no es diferente de determinar el fin en lo concreto, pero sí es diferente de determinar "los medios" que se ordenan al fin 36 .

\footnotetext{
32 Cfr. Ética a Nicómaco III 3, 1113a2-5.

33 Cfr. Ética a Nicómaco VI 13, 1144b20-25. Cfr., también, Suma teológica II-II, q. 47, a. 6, ad 3m.

34 Cfr. Ética a Nicómaco VI 13, 1144b1-14.

35 Cfr. Ética a Nicómaco VI 13, 1144b14-30.

36 Cfr. Suma teológica II-II, q. 47, a. 7: "per rectam dispositionem eorum quae sunt ad finem medium invenitur". Fabio Morales es una de las primeras personas a quien yo oí defender esta tesis. Lo hizo en La deliberación en la ética de Aristóteles, su trabajo de ascenso a Profesor Titular, presentado en el año 2002 al Departamento de Filosofía de la Universidad Simón Bolívar, pp. 67 y ss.; 152 y ss.; 158-162.
} 


\section{Conclusión}

Pienso que ahora estamos en condiciones de afirmar las siguientes tesis: Aristóteles no incurrió en la falacia naturalista, tal como la concibió G. E. Moore. El bien como trascendental se identifica con el ser, tanto en el sujeto como en la razón real significada, aunque no en la razón meramente intencional. Ser y bien se pueden conocer ambos con el intelecto en su función teórica o en su función práctica, y se puede afirmar proposicionalmente la realidad del bien. La frase "es preciso obrar conforme a la naturaleza" puede entenderse de una manera que no entrañe la falacia naturalista. La consideración del bien solo no puede dar lugar a una afirmación moral, pues se requiere la referencia del bien al agente y a su apetito. Sin embargo, lo que debe querer el apetito lo determina el intelecto al considerar diversos bienes reales en su relación y proporción con el agente y sus apetitos, de tal manera que las máximas morales, aun los principios primeros, proceden de la experiencia. Y, por último, la deliberación no está subsumida en el apetito, aunque no pueda haber virtud de la razón práctica sin rectitud del apetito.

$\mathrm{Y}$ con esto me parece que se ha aclarado apreciablemente el panorama en la consideración de este importante grupo de problemas planteados por numerosos autores contemporáneos, con ocasión de varios argumentos y reflexiones de G. E. Moore, David Hume e Immanuel Kant.

\section{Referencias bibliográficas}

Anscombe, E., Intention, Oxford University Press, Oxford, 1958.

AQuino, S.T. de, Quaestiones Disputatae De Veritate, www.corpus thomisticum.org AQuino, S.T. de, Scriptum super Sententiis, www.corpusthomisticum.org Aquino, S.T. de, Super Boëtii De Trinitate, www.corpusthomisticum.org Aquino, S.T. de, Summa Theologiae, www.corpusthomisticum.org ARISTóteles, Ethica Nicomachea, Oxford, Oxford University Press, 1970.

Casanova, C.A., "Una reconsideración del De Motu Animalium y el silogismo práctico", Pensamiento, Vol. 65, No. 44 (2009), pp. 339-353.

CASANOVA, C.A., "¿Por qué tiene tantas dificultades la razón natural en nuestra época para reconocer las doctrinas centrales de la encíclica Humanae Vitae?", en Razón y tradición. Estudios en honor de Juan Antonio Widow, Editorial Globo, Santiago, 2011, pp. 353-377.

FinNis, J., Natural Law and Natural Rights, Oxford University Press, Oxford, 1980. FinNis, J., Natural Law and Natural Rights, Oxford University Press, Oxford, 2011. GiLson, E.. El realismo metódico, Ediciones Rialp, Madrid, 1974.

Hume, D., An Inquiry Concerning the Human Understanding, en The Philosophical Works of David Hume Thoemmes Press, Bristol, 1996, Volume IV, pp. 1-226. 
Hume, D., Treatise of Human Nature Oxford University Press, Oxford, 1896, disponible en la "Online Library of Liberty".

Kant, I., Critique of Pure Practical Reason, en Critique of Practical Reason and Other Writings in Moral Philosophy, Garland Publishers INC., Nueva York, 1976, pp. 118-260.

Kant, I., Fundamentación de la metafísica de las costumbres, Encuentro, Madrid, 2003.

Kant, I., Metafísica de las costumbres, Adela Cortina y Jesús Conill Sancho (trads.), Editorial Tecnos, Madrid, 2008.

Kelsen, H., Teoría pura del Derecho, Editorial Trotta, Valladolid, 2011 (traducción de la primera edición de 1934).

Locke, J., Ensayos sobre el entendimiento humano, Fondo de Cultura Económica, Buenos Aires, 1956.

Massini Correas, C., La falacia de la falacia naturalista, Editorial Idearium, Mendoza, 1995.

MiLl, J.S., Utilitarianism, en Plamenatz, John (ed.). The English Utilitarians, Basil Blakcwell, Oxford, 1949, pp. 161-228.

Moore, G. E., Principia Ethica, Cambridge University Press, Cambridge, 1959.

Morales, F., La deliberación en la ética de Aristóteles. Trabajo de ascenso a Profesor Titular, presentado en el año 2002 al Departamento de Filosofía de la Universidad Simón Bolívar

Nussbaum, M., "Essay 4". En: Aristotle's De Motu Animalium, Princeton University Press, Princeton, 1978, pp. 165-220.

Silva, M., Derecho, poder y valores. Una visión crítica del pensamiento de Norberto Bobbio, Editorial Comares, Granada, 2008.

Simpson, P., "Saint Thomas and the Naturalistic Fallacy", The Thomist 51 (1984), pp. 51-69.

SteIn, E., Potenz und Akt. Studien zu einer Philosophie des Seins, ASW 18, 1998.

Teruel, P.J., "Edith Stein y el problema de la Konstitution", Diálogo filosófico 58 (2004), pp. 79-96.

Weber, M., "The Meaning of Ethical Neutrality in Sociology and Economics", en Max Weber on the Methodology of the Social Sciences, The Free Press of Glencoe, Illinois, 1949, pp. 1-47.

Carlos A. Casanova

Universidad Santo Tomás, Chile

Universidad Bernardo O'Higgins, Chile

carlosacasanovag@gmail.com 